\title{
Percutaneous transluminal coronary angioplasty in Nepalese diabetic patients: Do they carry extra risk to revascularization process?
}

\author{
Khatun F1, Rawat $B^{2}$, Vaidya $A^{3}$, Rajbhandari $S^{4}$, Bhatta $Y^{5}$ \\ ${ }^{1}$ Medical officer, ${ }^{2}$ Chief, Cardiology Department, ${ }^{3}$ Research Consultant in Cardiovascular Epidemiology, \\ ${ }^{4}$ Consultant Cardiologist, ${ }^{5}$ Chief, Invasive Cardiology, Norvic International Hospital, Thapathali, Kathmandu
}

\begin{abstract}
Background and Objectives: There is evidence that diabetes carries risk of various complications and adverse outcome with coronary revascularisation procedures. The aim of this study was to analyze the outcomes and complications of Percutaneous Transluminal Coronary Angioplasty in Nepalese diabetic patients compared to non-diabetic patients. Method: A hospital-based comparative cross-sectional study was conducted at Norvic International Hospital, Kathmandu, Nepal. A total of 702 consecutive Percutaneous Transluminal Coronary Angioplasty patients coming to the hospital from 2002 to 2010 were included. Angioplasty was performed using radial and femoral routes in a standard setting with standard techniques. Information on other background risk factors was recorded. Success of the procedures and presence of major and minor complications were observed.

Results: Of the 702 patients participating in this study, 259 were diabetic and 443 were non-diabetic. Success rates were similar: 256 (98.8\%) of diabetic and 438 (98.8\%) of non-diabetic had a successful Percutaneous Transluminal Coronary Angioplasty. Complications of the procedure were however higher in the diabetic patients with higher in-hospital death (odds ratio 3.4, 95\% confidence Interval: 0.6-19.1), compared to non-diabetic patients.

Conclusion: The overall outcome of Percutaneous Transluminal Coronary Angioplasty was equally successful in diabetic and non-diabetic populations groups. But the complications were higher with the diabetic group which was because of presence of other co-morbidities in this group and were not procedure-related.
\end{abstract}

Key words: Diabetes mellitus, Nepal, Percutaneous Transluminal Coronary Angioplasty

\section{Introduction}

$\mathrm{C}^{\circ}$ oronary Artery Disease (CAD), also known as Coronary Heart Disease (CHD) or Atherosclerotic heart disease is a pathological condition which compromises the arterial supply of oxygen and nutrients to the myocardium as a result of accumulation of atheromatous plaque within the coronary arteries, narrowing its lumen. CAD is almost always caused by atheroma or its complication such as thrombosis and coronary artery spasm. The severity of CAD varies according to the progress of the atherosclerotic changes which could be partial to complete obstruction of the lumen, leading to varying degree of symptoms. There

\footnotetext{
Address for correspondence

Dr. Bharat Rawat,

Chief, Cardiology Department,

Norvic International Hospital, Thapathali, Kathmandu

E-mail: drrawat@norvic.wlink.com.np
}

can be various consequences of CAD, which are stable angina, unstable angina and myocardial infarction. CAD is also the most common cause of sudden death'.

Diabetes mellitus is strongly associated with cardiovascular disease ${ }^{2}$. Diabetes confers an increase in risk of vascular disease and cardiovascular problems by two-folds ${ }^{3}$. Hyperglycemia, dyslipidemia, atherosclerotic changes associated with diabetes subjects to microvascular and macrovascular diseasesnephropathy, retinopathy, stroke and CAD. Diabetic patients have a higher incidence of unstable plaques, which are vulnerable to abrupt rupture; leading to closure of coronary artery and resultant acute myocardial infarction. Also, diabetic patients have increased blood viscosity, enhanced platelet aggregation and increased synthesis of thromboxane $A_{2}$, which further favours platelet aggregation and coronary spasm at the site of 
fissure and rupture. In addition, fibrinogen levels are relatively elevated in diabetic patients along with factor VIII and fibrinopeptide A levels. Endothelial dysfunction may be more pronounced in diabetics, and endogenous fibrinolysis is also impaired ${ }^{4-8}$. Diabetic patients are predisposed to acute myocardial infarction (AMI) and that the mortality rate of AMI is significantly increased among diabetic patients 9 .

Percutaneous Transluminal Coronary Angioplasty (PTCA) is a revascularisation technique in the patient with significant CAD. This is a procedure where a catheter is introduced to the stenosed coronary artery and a balloon is inflated at the stenosed part which breaks the plaque and dilates the artery. The procedure is invariably augmented by "Stenting" where upon a mesh wire is slipped into the stenosed part to keep it dilated and prevent the risk of restenosis ${ }^{10-13}$. For some forms of CAD, PTCA with stenting is a good alternative to heart surgery ${ }^{14,15}$. In acute cases, PTCA with stenting has proved to show a small but a definitive reduction in mortality as compared to other medical therapies like administration of thrombolytic agents ${ }^{16}$.

CAD is the leading cause of death in the developed countries. But with the change of lifestyle, dietary habits and improving medical facilities which in turn increase the lifespan, even in a developing country like Nepal, a significant increase in cardiac related ailments has been noted. PTCA is being practiced in Nepal only since the turn of the millennium. So far there has been no study to observe if the Nepalese diabetic patients have a differing response to the procedure. Hence, a study was undertaken with the objective to compare the outcome of PTCA among diabetic and non-diabetic patients and the incidence of other risk factors among the two groups.

\section{Materials and Methods}

Seven hundred and two consecutive patients who underwent PTCA at Norvic International Hospital, Kathmandu, Nepal, over a period of 8 years, from 2002 to 2010 , were studied retrospectively.

The patients who were already a diagnosed case of diabetes under anti-diabetic medications including insulin, or newly diagnosed diabetics on hospital admission, both were classified as diabetics. A case was diagnosed as diabetes ${ }^{17}$ demonstrating any of the following: Fasting blood sugar > $126 \mathrm{mg} / \mathrm{dL}$, Random blood sugar level $>200 \mathrm{mg} / \mathrm{dL}$, blood sugar after glucose tolerance test (GTT) $>200 \mathrm{mg} / \mathrm{dl}$ and glycosylated hemoglobin level $(\mathrm{HbA} 1 \mathrm{C}) \geq 6.5 \%$. Patients were classified as hypertensive ${ }^{18}$, who were already old cases under medications or newly diagnosed case with systolic blood pressure $>140 \mathrm{mmHg}$ or diastolic blood pressure $>90 \mathrm{mmHg}$.

All patients with past history of smoking and current smokers were classified as Smokers. Dyslipidemia was defined as having a Total Cholesterol $>200$ mg\%, lowdensity lipoprotein $>100 \mathrm{mg} \%$, triglycerides $>150 \mathrm{mg} \%$, high density lipoprotein $<40 \mathrm{mg} \%{ }^{19}$. A positive family history was noted for those cases who gave a history of first degree relative having CAD before the age of 60 years.

PTCA was performed using radial and femoral routes in a standard setting with standard techniques. A proper consent was taken with every patient after briefing about the procedure. Outcome of the procedure was labelled 'successful' if there was no residual stenosis and a brisk antegrade flow was seen at the end of the procedure. Complications of the procedure were categorized as major complications such as in-hospital death, sub/ acute thrombosis, ventricular tachycardia or ventricular fibrillation; and minor complications such as need for blood transfusion, gastro-intestinal bleeding and groin hematoma formation.

Data was entered in SPSS 11.5 version. Results are expressed as mean with standard deviations, proportions, and odds ratios with 95\% confidence intervals.

\section{Results}

Clinical and demographic characteristics of diabetic and non-diabetic patients are summarized in Table 1. Out of the 702 patients that underwent PTCA, 259 (37\%) patients had diabetes. There was no statistical difference in the mean age between the two populations. Compared to the non-diabetics, diabetic patients had higher risk of other cardiac risk factors like smoking (34\% vs. $32.5 \%)$, hypertension ( $79.5 \%$ vs. $57.8 \%)$, dyslipidemia $(38.8 \%$ vs. $29.2 \%)$ and a positive family history $(9.3 \%$ vs. $8.8 \%)$.

The procedural success and in-hospital complications are summarized in Table 2 . The procedure was equally successful in both diabetic and non-diabetic populations (98.8\% vs. $98.8 \%$ ). However, in-hospital death was higher in diabetic patients ( $1.5 \%$ vs. $0.5 \%$ ).

\section{Discussion}

Numerous studies worldwide have shown various impacts of diabetes on the outcome of PTCA. Little is known about how far the result of these studies imply 
Khatun F et. al.

Table 1: Risk factors in diabetic and non-diabetic patients undergoing PTCA

\begin{tabular}{|c|c|c|c|c|c|}
\hline & \multicolumn{2}{|c|}{ Diabetic } & \multicolumn{2}{|c|}{ Non-Diabetic } & \multirow{2}{*}{$\begin{array}{c}\text { Odds Ratio (95\% CI) [diabetic vs. non- } \\
\text { diabetic) }\end{array}$} \\
\hline & $\mathbf{N}$ & $\%$ & $\mathbf{N}$ & $\%$ & \\
\hline \multicolumn{6}{|l|}{ Sex } \\
\hline Male & 213 & 82.2 & 362 & 81.7 & \multirow{2}{*}{$1.0(0.7-1.5)$} \\
\hline Female & 43 & 17.8 & 81 & 18.3 & \\
\hline \multicolumn{6}{|c|}{ Age (years) } \\
\hline Mean/SD & \multicolumn{2}{|c|}{$60.2 / 9.6$} & \multicolumn{2}{|c|}{$59.1 / 10.5$} & - \\
\hline \multicolumn{6}{|l|}{ Smoking } \\
\hline Yes & 88 & 34.0 & 144 & 32.5 & \multirow{2}{*}{$1.1(0.8-1.5)$} \\
\hline No & 171 & 66.0 & 299 & 67.5 & \\
\hline \multicolumn{6}{|c|}{ Hypertension } \\
\hline Yes & 206 & 79.5 & 256 & 57.8 & \multirow{2}{*}{$2.6(1.8-3.6)$} \\
\hline No & 53 & 20.5 & 187 & 42.2 & \\
\hline \multicolumn{6}{|c|}{ Dyslipidemia } \\
\hline Yes & 109 & 38.8 & 136 & 29.2 & \multirow{2}{*}{$1.5(1.1-2.1)$} \\
\hline No & 172 & 61.2 & 330 & 70.8 & \\
\hline \multicolumn{6}{|c|}{ Family History } \\
\hline Yes & 24 & 9.3 & 39 & 8.8 & \multirow{2}{*}{$1.1(0.6-1.8)$} \\
\hline No & 235 & 90.7 & 404 & 91.2 & \\
\hline Total & 259 & 100 & 443 & 100 & \\
\hline
\end{tabular}

SD: Standard Deviation, Cl: Confidence Interval

Table 2: Outcome and Complications in diabetic and non-diabetic patients undergoing PTCA

\begin{tabular}{|c|c|c|c|c|c|}
\hline & \multicolumn{2}{|c|}{ Diabetic } & \multicolumn{2}{|c|}{ Non-Diabetic } & \multirow{2}{*}{$\begin{array}{c}\text { Odds ratio (95\% Cl) [diabetic vs. } \\
\text { non-diabetic) }\end{array}$} \\
\hline & $\mathbf{N}$ & $\%$ & $\mathbf{N}$ & $\%$ & \\
\hline \multicolumn{6}{|l|}{ Outcome } \\
\hline Successful & 256 & 98.8 & 438 & 98.8 & \multirow{2}{*}{$0.9(0.2-4.1)$} \\
\hline Unsuccessful & 3 & 1.2 & 5 & 1.1 & \\
\hline \multicolumn{6}{|c|}{ In-Hospital Death } \\
\hline Yes & 4 & 1.5 & 2 & 0.5 & \multirow{2}{*}{$3.4(0.6-19.1)$} \\
\hline No & 255 & 98.5 & 441 & 99.5 & \\
\hline \multicolumn{6}{|c|}{ Sub/Acute Thrombosis } \\
\hline Yes & 1 & 0.4 & 2 & 0.5 & \multirow{2}{*}{$0.8(0.1-9.4)$} \\
\hline No & 258 & 99.6 & 441 & 99.5 & \\
\hline \multicolumn{6}{|l|}{ VT/VF } \\
\hline Yes & 0 & 0 & 2 & 0.5 & \multirow{2}{*}{-} \\
\hline No & 259 & 100 & 441 & 99.5 & \\
\hline \multicolumn{6}{|c|}{ Blood Transfusion } \\
\hline Yes & 1 & 0.4 & 1 & 0.2 & \multirow{2}{*}{$1.7(0.1-27.5)$} \\
\hline No & 258 & 99.6 & 442 & 99.8 & \\
\hline \multicolumn{6}{|l|}{ GI bleeding } \\
\hline Yes & 0 & 0 & 1 & 0.2 & \multirow{2}{*}{-} \\
\hline No & 259 & 100 & 442 & 99.8 & \\
\hline \multicolumn{6}{|c|}{ Groin Hematoma } \\
\hline Yes & 1 & 0.4 & 0 & 0 & \multirow{2}{*}{-} \\
\hline No & 258 & 99.6 & 443 & 100 & \\
\hline Total & 259 & 100 & 443 & 100 & \\
\hline
\end{tabular}

$\mathrm{Cl}$ :Confidence Interval 
to the Nepalese population. Norvic Hospital is the first in private setting to introduce cardiac procedures in Nepal. The study was designed to evaluate the risk of outcome and complications of the procedure in Nepalese diabetic patients and compare it with non-diabetic patients.

A significantly more adverse long term outcome is experienced by diabetic patients as compared to the non diabetic patients, whether it is PTCA or Coronary Artery Bypass Surgery (CABG). In spite of this, diabetic patients continue to need revascularization for symptomatic improvement because of favourable short term outcome, and a boon for improving the quality of life. Various studies ${ }^{20-23}$ have described the clinical characteristics, demographics, lesional characteristics and acute and long term outcomes of PTCA in diabetes. The BARI trial ${ }^{24}$, which was conducted in pre stent era, shows superiority of CABG over PTCA alone (without stent) and the need for additional revascularization was also higher in diabetics undergoing PTCA. But with the evolution of stent era, the revascularisation rate has significantly decreased but still the mortality and revascularization rate is higher in diabetics as compared to non-diabetics.

Studies from other centres have also shown a comparable procedural success but higher in-hospital deaths among the diabetic cases. A study done in Jefferson Medical College, Philadelphia ${ }^{25}$ showed low but comparably equal success rate in diabetic and non diabetic patients $(71 \%$ vs. $76 \%)$ and estimated in hospital death rate was tripled in diabetic patients. On nine years follow up, mortality was twice higher in diabetic patients $(36 \%$ vs. $18 \%$ ) with higher risk of late myocardial infarction. Another study in University of Pittsburg, USA ${ }^{20}$, showed equal angiographic success in both diabetic and non diabetic groups, but there were more in-hospital deaths and myocardial infarction in the diabetic group. Similarly, another study in Atlanta ${ }^{21}$ showed high success and low complications rates in both diabetic and non diabetic subjects but higher rate of myocardial infarction and repeat revascularization in diabetic patients.

Some studies have however shown similar clinical outcomes for both diabetic and non-diabetic groups. A Chinese study ${ }^{22}$ revealed not only equally successful procedures in diabetic and non diabetics $(89.6 \%$ vs. $90.3 \%$ ), the overall PTCA complications were also similar in both groups. Similarly, in another study ${ }^{23}$ conducted in USA in 4 different community cardiac catherization laboratory from different states, there were no significant differences in clinical outcome and complications between two populations. In fact, diabetic patients had less in-hospital mortality (1.08 vs. 1.29). However, on one year follow up, diabetic patients were more likely to have CAD progression with higher rate of repeat PTCA (31.7\% vs. $27.3 \%$ ) and CABG surgery (10.1\% vs. $4.5 \%)$.

This study was done on a limited 702 patients from Nepal and covered only the early complications of the procedures limited to the hospital stay. The study lacks long term follow-up results. This study does not cover various other complications of the procedure like restenosis (early/late) and the need for repeat revascularization.

\section{Conclusion}

The study showed that the immediate success of PTCA was similar in diabetic and non-diabetic patients though the diabetic patients carried higher risk of complications because of the co-morbid conditions. We conclude that diabetes does not increase/decrease the rate of outcome associated with the PTCA procedure than the nondiabetic patients. Diabetes should not be considered a negative factor to delay or refrain to attempt PTCA in a patient and clinicians should equally attempt PTCA in diabetic and non-diabetic patients.

\section{References}

1. Thomas AC, Knapman PA, Krikler DM, Davies MJ. Community study of the causes of natural sudden death. BMJ. December 1988;297(6661):1453-6. doi:10.1136/bmj.297.6661.1453. PMID 3147014.

2. Santaguida PL, Balion C, Hunt D, Morrison K, Gerstein $H$, Raina P, Booker L, Yazdi H. Diagnosis, prognosis, and treatment of impaired glucose tolerance and impaired fasting glucose. Summary of Evidence Report/Technology Assessment [Internet] Rockville (MD): Agency for Health Research and Quality; 2005 Aug [cited 2008 Jul 20]. Report No.: 128. Available

from: http://www.ahrq.gov/clinic/epcsums/ impglusum.htm.

3. The Emerging Risk Factors Collaboration. Diabetes mellitus, fasting blood glucose concentration, and risk of vascular disease: a collaborative meta-analysis of 102 prospective studies. The Lancet [Internet]. 2010 [cited 2008 Jul 20];375:2215-22. Available from: http://www.thelancet.com/journals/lancet/ article/PIIS0140-6736\%2810\%2960484-9/fulltext.

4. MacRury S, Lowe G. Blood rheology in diabetes mellitus. Diabet Med. 1990; 7:285-91. 
5. Davies M, Bland J, Hangartner J, Angelini A, Thomas A. Factors influencing the presence or absence of acute coronary artery thrombi in sudden ischaemic death. Eur Heart J. 1989;10:203-8.

6. Ostermann $\mathrm{H}$, van der Loo J. Factors of the hemostatic system in diabetic patients. Haemostasis. 1986;16:386-416.

7. Breddin H, Krzywanek H, Althoff P, Schoffling K, Ubeila K. PARD: platelet aggregation as a risk factor in diabetes-results of a prospective study. Horm Metab Res. 1985;15(suppl):63-8.

8. Davi G, Catalano I, Averna M, Notobartolo A, Stano A, Ciabottoni G. Thromboxane biosynthesis and platelet function in type II diabetes mellitus. N Engl J Med. 1990;322:1769-74.

9. Rytter L, Troelsen S, Beck-Nielsen H. Prevalence and mortality of acute myocardial infarction in patients with diabetes [Abstract]. Diabetes Care. 1985;8:230-4.

10. Nobuyoshi M, Kimura $\mathrm{T}$, Nosaka $\mathrm{H}$ et al. Restenosis after successful percutaneous transluminal coronary angioplasty: serial angiographic follow-up of 229 patients. J Am Coll Cardiol. 1988;12:616-23.

11. Serruys PW, De Jaegere $P$, Kiemeneij $F$ et al. for the BENESTENT Study Group. A comparison of balloon expandable stent implantation with balloon angioplasty in patients with coronary artery disease. N Engl J Med. 1994;331:489-95.

12. Fischman $D L$, Leon $M B$, Baim DS, Schatz RA, Savage MP, Penn I et al, for the stent restenosis study investigators. A randomized comparison of coronary-stent placement and balloon angioplasty in the treatment of coronary artery disease. N Engl J Med. 1994;331:496-501.

13. Serruys PW, de Jaegere $P$, Kiemeneij $F$, Magaya C, Rutsch W, Heyndrickx $G$ et al for the Benestent Study Group. A comparison of balloon-expandablestent implantation with balloon angioplasty in patients with coronary artery disease. N Engl J Med. 1994;331:489-95.

14. Michaels AD, Chatterjee K. Cardiology patient pages. Angioplasty versus bypass surgery for coronary artery disease [Internet]. Circulation. 2002 Dec;106(23):e187-90. doi: 10.1161/01. CIR.0000044747.37349.64. PMID 12460885. Available from: http://circ.ahajournals.org/cgi/ content/full/106/23/e187. Retrieved 2009-07-13.

15. Mercado, N, Flather, MD, Boersna, E, et al. on Behalf of the Trial Investigators CABG vs Stenting for Multivessel Disease: a Meta-analysis of ARTS-1, SoS, ERACI-2, and MASS-2, Presentation at European Society of Cardiology Congress 2003.

16. Weaver WD, Simes RJ, Betriu A et al. Comparison of primary coronary angioplasty and intravenous thrombolytic therapy for acute myocardial infarction: a quantitative review. JAMA. 1997 Dec;278(23):2093-8. doi:10.1001/jama.278.23.2093. PMID 9403425.

17. World Health Organization Department of Noncommunicable Disease Surveillance. Definition, Diagnosis and Classification of Diabetes Mellitus and its Complications. World Health Organization 1999.

18. Carretero OA, Oparil S. Essential hypertension. Part I: definition and etiology. Circulation [Internet]. 2000 Jan;101(3):329 35. PMID 10645931. Available from: http://circ.ahajournals.org/cgi/pmidlookup?v iew=long\&pmid=10645931.

19. National Heart, Lung, and Blood Institute. National Cholesterol Education Program. National Cholesterol Education Program Expert Panel on Detection, Evaluation, and Treatment of High Blood Cholesterol in Adults. NIH Publication No. 01-3670. http://www.nhlbi.nih.gov/about/ncep/ ncep_pd.htm

20. Kip KE, Faxon DP, Detre KM, Yeh W, Kelsey SF, Currier JW, for the Investigators of the NHLBI PTCA Registry. Coronary angioplasty in diabetic patients: the National Heart, Lung, and Blood Institute Percutaneous Transluminal Coronary Angioplasty Registry. Circulation. 1996;94:1818-25.

21. Stein $B$, Weintraub WS, Gebhart $S$, Cohen-Bernstein $\mathrm{CL}$, Grosswald R, Liberman HA, Douglas JS, Morris DC, King SB III. Influence of diabetes mellitus on early and late outcome after percutaneous transluminal coronary angioplasty. Circulation. 1995;91:979-89.

22. Li C, Gao R, Yang Y, Chen J, Qin X, Xu B, et al. The influence of diabetes mellitus on the procedural and in-hospital outcomes after elective percutaneous coronary intervention. Chinese Medical Journal. 2005; 118(14):1220-4.

23. Kugelmass AD, Cohen DJ, Houser F, Mack M, Simon AW, Battaglia SL, et al . The Influence of Diabetes Mellitus on the Practice and Outcomes of Percutaneous Coronary Intervention in the Community: A Report from the HCA Database. J Invasive Cardiol. 2003;15(10).

24. The BARI Investigators. Influence of diabetes on 5-year mortality and morbidity in a randomized trial comparing coronary artery bypass grafting and percutaneous transluminal coronary angioplasty in patients with multivessel disease. Circulation. 1997;96:1761-9.

25. Goldberg S, Savage MP, Fischman DL. The Interventional Cardiologist and the Diabetic Patient Have We Pushed the Envelope Too Far or Not Far Enough? Circulation. 1996;94:1804-6. 